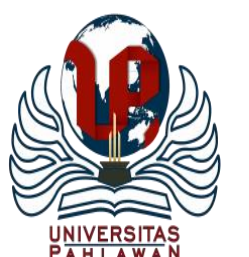

Jurnal Abdidas Volume 2 Nomor 4 Tahun 2021 Halaman 821-828

JURNAL ABDIDAS

http://abdidas.org/index.php/abdidas

\title{
Pemanfaatan Media Pembelajaran Berbasis Multimediapada Era Pandemi Covid-19 di Taman Kanak-kanak
}

\author{
Edwin Zusrony ${ }^{1}$, Dewi Widyaningsih ${ }^{2}$ \\ Bisnis, Fakultas Komputer dan Bisnis, Universitas Sains dan Teknologi Komputer, Indonesia ${ }^{1,2}$ \\ Email : $\underline{\text { edwin.zusrony@stekom.ac.id }} \underline{\text { dewi@ stekom.ac.id }}^{2}$
}

\begin{abstract}
Abstrak
Guru Taman Kanak-kanak (TK) sebagai pengajar profesional berperan sebagai tenaga pendidik yang dituntut berpikir kreatif dalam membuat berbagai media pembelajaran yang efektif dan efisien bagi para murid pra sekolah dasar agar bisa memahami materi yang diberikan. Peningkatan kemampuan guru-guru TK dalam adaptasi teknologi, khususnya mengembangkan media pembelajaran berbasis multimedia untuk mendukung sistem Belajar dari Rumah (BDR) di era pandemi Covid-19. Kondisi pembelajaran TK Tarbiyatul Banin 58 di Kota Salatiga, Jawa Tengah saat ini hanya memanfaatkan aplikasi WhatsApp (WA) untuk melakukan interaksi pembelajaran dengan orang tua murid. Dalam melaksanakan pembelajaran daring (online) sekolah memiliki fasilitas yang mendukung seperti laptop atau notebook tetapi belum secara optimal pengaplikasiannya. Dalam pelaksanaan kegiatan pengabdian masyarakat di TK Banin 58 tim dari Universitas STEKOM menggunakan metode penyuluhan terkait pemanfaatan media sosial seperti YouTube dan Google Drive sebagai alternatif pembelajaran berbasis multimedia untuk menunjang tercapainya tujuan pembelajaran. Setelah kegiatan dilaksanakan para guru-guru sangat antusias serta bersemangat ingin segera menerapkan ilmu yang telah didapat untuk segera diterapkan pada sistem Belajar dari Rumah (BDR).
\end{abstract}

Kata kunci: media pembelajaran, multimedia, taman kanak-kanak, Covid-19

\begin{abstract}
Kindergarten teachers as professional teachers act as educators who are required to think creatively in making various effective and efficient learning media for pre-primary school students in order to understand the material provided. Improving the ability of kindergarten teachers in adapting technology, especially developingmultimedia-based learning media to support the learning from home (BDR) system in the Covid-19 pandemic era. The learning conditions of Tarbiyatul Banin 58 Kindergarten in the city of Salatiga, Central Java currently only use the WhatsApp (WA) application to conduct learning interactions with parents. In carrying out online learning, schools have supporting facilities such as laptops or notebooks, but their application is not optimal. With conditions where many teachers are still lacking in making multimedia-based learning media. Therefore, the team from STEKOM University tried to offer counseling related to the use of social media such as YouTubeand Google Drive as an alternative to multimedia-based learning to support the achievement of learning objectives.
\end{abstract}

Keywords: learning media, multimedia, kindergarten, Covid-19

Copyright (c) 2021 Edwin Zusrony, Dewi Widyaningsih

$\square$ Corresponding author :

Address : Universitas STEKOM

Email : edwin.zusrony@stekom.ac.id

ISSN 2721-9224 (Media Cetak)

DOI $\quad:$ https://doi.org/10.31004/abdidas.v2i4.369

\author{
ISSN 2721- 9216 (Media Online)
}


822 Kemandirian Pemanfaatan Media Pembelajaran Berbasis Multimedia Pada Era Pandemi Covid-19 di Taman Kanak-kanak - Edwin Zusrony, Dewi Widyaningsih

DOI: https://doi.org/10.31004/abdidas.v2i4.369

\section{PENDAHULUAN}

Dunia saat ini sedang dilanda pandemi besar yang mengubah tatanan baru dalam seluruh kehidupan manusia, khususnya mobilitas atau pergerakan manusia. Interaksi antar manusia dibatasi dengan adanya pandemi Covid-19. Hal ini juga berdampak salah satunya pada dunia pendidikan, di mana pembelajaran di Indonesia dituntut tidak dilakukan secara face to face (Busa, 2020). Pandemi Covid-19 membuat para generasi muda khususnya pendidikan dasar sangat sulit beradaptasi di mana seharusnya mereka membutuhkan interaksi tatap muka dalam pembelajaran. Secara garis besar dengan adanya pandemi maka menjaga jarak (social distancing) wajib dilakukan di mana pembelajaran secara tatap muka ditiadakan dan diganti dengan pembelajaran secara daring atau online (Sibero \& Manurung, 2020).

Perkembangan informasi yang semakin cepat menuntut setiap orang bisa mendapatkan sumber informasi melalui media internet yang cepat, murah, dan mudah. Salah satu pengembangannya dalam dunia pendidikan salah satunya media pembelajaran berbasis multimedia. Para guru dan murid dituntut belajar secara cepat dan adaptif terhadap penggunaan berbagai aplikasi yang mendukung pembelajaran jarak jauh atau daring. Dalam era industri 4.0 bisa memberikan sebuah solusi dan dengan digitalisasi, maka akan lebih efisien dan efektif tanpa terbatas oleh ruang dan waktu (Ismail et al., 2021). Pembelajaran secara online dapat dimanfaatkan sebagai solusi menghadapi pandemi. Teknologi informasi serta komunikasi juga dapat digunakan sebagai platform dalam pembelajaran, baik yang online maupun offline (Hamidah \& Marsiah, 2020).

Saat ini, para guru memiliki sebuah tuntutan mampu dalam mengembangkan dan mengaplikasikan berbagai alat-alat dalam pembelajaran di sekolah sesuai dengan tuntutan zaman yang berkembang saat ini (Nugraha \& Sudiyono, 2018). Pengembangan media pembelajaran yang diharapkan di era pandemi Covid-19 adalah yang kreatif, inovatif dan adaptif dengan perkembangan teknologi pembelajaran masa kini. Keterbatasan sarana dan prasarana sekolah, khususnya sekolah swasta membuat permasalahan ini semakin kompleks.

TK Tarbiyatul Banin 58 di Kota Salatiga provinsi Jawa Tengah merupakan salah satu sekolah swasta pendidikan anak usia dini yang terkena dampak dari pembelajaran secara daring. Dengan biaya operasional sekolah yang terbatas, kurangnya sarana dan prasarana pembelajaran multimedia, serta masih kurangnya pemahaman terkait adaptasi teknologipembelajaran multimedia interaktif membuatbeban semakin berat.

Berdasarkan permasalahan di atas, maka Lembaga Penelitian dan Pengabdian Masyarakat (LPPM) yang diwakili oleh dosen dari Program Studi Bisnis, Fakultas Komputer dan Bisnis, Universitas STEKOM (Sains dan Teknologi Komputer) ingin mengadakan pengabdian kepada masyarakat. Kegiatan ini dilaksanakan selain sebagai kewajiban seorang dosen dalam menjalankan Tri Dharma perguruan tinggi. Selain itu sebagai sesama organisasi yang bergerak di bidang pendidikan, kami merasa terpanggil untuk bisa memberikan sedikit ilmu serta pengetahuan 
823 Kemandirian Pemanfaatan Media Pembelajaran Berbasis Multimedia Pada Era Pandemi Covid-19 di Taman Kanak-kanak - Edwin Zusrony, Dewi Widyaningsih

DOI: https://doi.org/10.31004/abdidas.v2i4.369

kami agar dapat bermanfaat bagi masyarakat, khususnya TK Tarbiyatul Banin 58.

\section{METODE}

Dalam menyampaikan materi pemanfaatan media sosial sebagai media pembelajaran berbasis multimedia sebagai suatu solusi dalam pelaksanaan program Belajar dari Rumah (BDR) di era pandemi Covid-19 dengan metode tatap muka serta tetap menjalankan Protokol Kesehatan (PROKES). Dalam kegiatan pengabdian kepada masyarakat yang dilaksanakan di lingkungan TK Tarbiyatul Banin 58 di Kota Salatiga, Jawa Tengah dengan pemateri atau narasumber dari Dosen Program Studi BisnisUniversitas STEKOM Semarang.

Program pengabdian kepada masyarakat di TK Tarbiyatul Banin 58 terdapat beberapa tahapan sebagai berikut :

1) Tahap Pertama

Merupakan tahap persiapan kegiatan pengabdian kepada masyarakat, di mana para narasumber menyiapkan berbagai materi yang akan disampaikan dengan berbagai media seperti PowerPoint (PPT) dan audio visual serta menyiapkan sesi tanya jawab untuk merespon feedback dari para peserta.

2) Tahap Kedua

Merupakan tahap pelaksanaan kegiatan pengabdian kepada masyarakat, di mana tim dari Dosen Program Studi Bisnis Universitas STEKOM melakukan pelatihan media pembelajaran berbasis multimedia menggunakan aplikasi YouTube dan Google
Drive kepada guru-guru TK Tarbiyatul Banin58 Kota Salatiga, Jawa Tengah.

3) Tahap Ketiga

Merupakan tahap evaluasi pelaksanaan kegiatan pengabdian kepada masyarakat kepada para guru TK Tarbiyatul Banin 58, terkait kemampuan akhir setelah mendapatkan materi penyuluhan serta pelatihan dan kepuasan dalam menjalani kegiatan ABDIMAS ini.

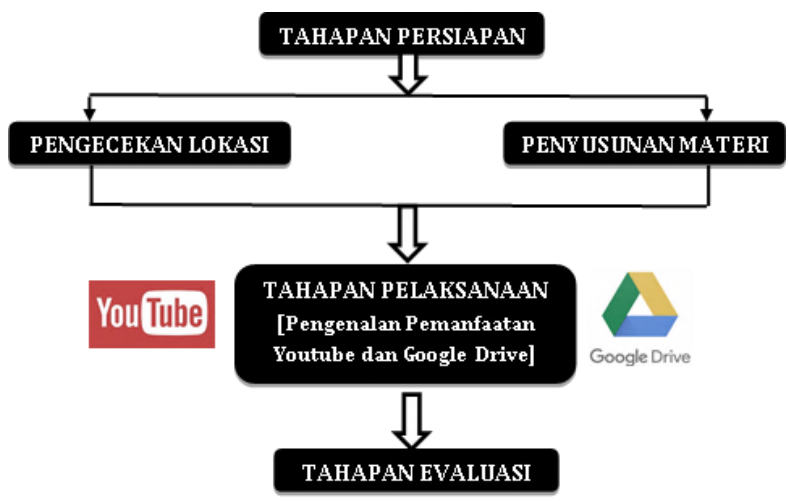

Gambar 1. Tahapan Kegiatan ABDIMAS

\section{HASIL DAN PEMBAHASAN}

Dalam pelaksanaan kegiatan pengabdian kepada masyarakat ini, para narasumber atau pemateri merancang sesuai kebutuhan dari mitra sekolah TK dalam hal pemanfaatan media sosial sebagai media pembelajaran berbasis multimedia. Penyuluhan yang disertai pelatihan singkat selama satu hari diharapkan berdampak pada peningkatan kemampuan para guru TK dalam memanfaatkan media sosial sebagai media pembelajaran yang efektif serta efisien. Hal ini senada dengan kebijakan dari pemerintah pusat yang menetapkan pembelajaran secara online (daring) mulai dari jenjang TK sampai dengan tingkat universitas 
(Wardani \& Ayriza, 2021).

Kegiatan pengabdian kepada masyarakat dilaksanakan di TK Tarbiyatul Banin 58 Kota Salatiga dilaksanakan pada hari Jumat tanggal 4 Desember 2020 dan diikuti oleh 12 orang peserta dari para guru dengan menjalankan Protokol Kesehatan (PROKES). Semua peserta dan pemateri diwajibkan selalu menjaga kebersihan dengan mencuci tangan dengan sabun sebelum kegiatandimulai dan selalu memakai masker. Pada saat kegiatan penyuluhan serta pelatihan dimulai para peserta juga diwajibkan untuk mengisi daftar peserta agar kegiatan ini dapat terdokumentasi dengan baik.

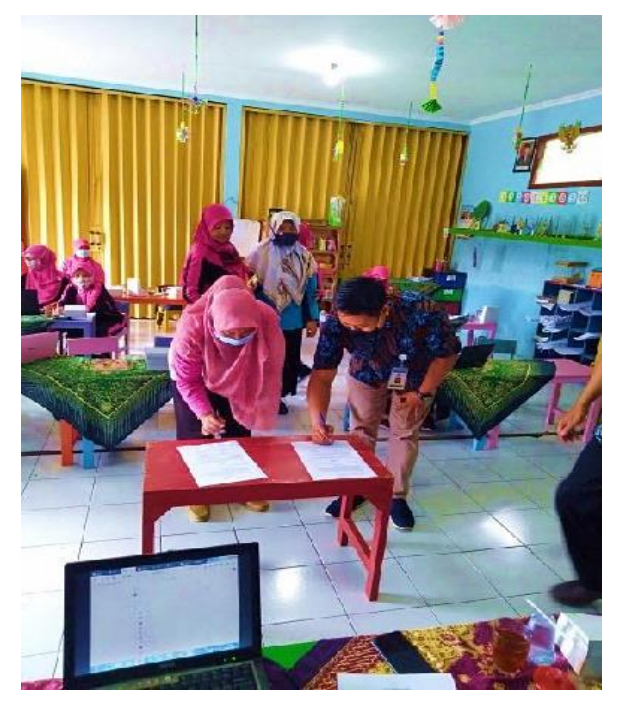

Gambar 2. Mengisi Daftar Hadir Kegiatan

Sebelum dilaksanakan kegiatan penyuluhan serta pelatihan pengabdian kepada masyarakat di TK Tarbiyatul Banin 58 Kota Salatiga, pemateri sempat menanyakan beberapa pertanyaan terkait pemahaman para guru-guru TK pada aplikasi media sosial seperti YouTube Channel dan Google Drive. Sebagian besar mengetahui terkait
YouTube Channel tetapi tidak semuanya paham akan cara membuatnya dan banyak yang belum memiliki akun. Sedangkan untuk Google Drive hanya beberapa orang saja yang memiliki, tetapi tidak semuanya memahami cara penggunaanya dalam mendukung proses Belajar dari Rumah (BDR).

Tabel 1. Tingkat Pengenalan Kepemilikan Akun

\begin{tabular}{|c|l|c|c|c|c|}
\hline No. & Akun & $\begin{array}{c}\text { Mem } \\
\text { iliki }\end{array}$ & $\begin{array}{c}\text { Tidak } \\
\text { Memiliki }\end{array}$ & $\begin{array}{c}\text { Meng } \\
\text { enal }\end{array}$ & $\begin{array}{c}\text { Tidak } \\
\text { Menge } \\
\text { nal }\end{array}$ \\
\hline 1. & $\begin{array}{l}\text { YouTube } \\
\text { Channel }\end{array}$ & $20 \%$ & $20 \%$ & $100 \%$ & $0 \%$ \\
\hline 2. & $\begin{array}{l}\text { Google } \\
\text { Drive }\end{array}$ & $30 \%$ & $70 \%$ & $30 \%$ & $70 \%$ \\
\hline
\end{tabular}

Pembukaan kegiatan acara pengabdian kepada masyarakat dimulai dengan kata sambutan oleh ketua tim ABDIMAS dari Universitas STEKOM. Acara dilanjutkan dengan penyampaian tujuan dan sasaran yang hendak dicapai dari kegiatan ini, di mana sangatlah penting bagi para guru zaman sekarang untuk lebih melek teknologi khususnya media pembelajaran berbasis multimedia.

Acara selanjutnya, langsung pada inti materi tentang pengenalan Google Drive dan pelatihan membuat akun Google Drive untuk sekolah TK Tarbiyatul Banin 58 Kota Salatiga. Pengenalan Google Drive ini dilakukan karena Google Drive merupakan salah satu media ajar yang berbasis e-learning, di mana akan dapat meningkatkan proses dalam belajar mengajar (Retnoningsih, Retnoningsih, Solikin, Muis, \& Widiawati, 2021). Google Drive sendiri merupakan salah satu platform yang cocok dalam 
825 Kemandirian Pemanfaatan Media Pembelajaran Berbasis Multimedia Pada Era Pandemi Covid-19 di Taman Kanak-kanak - Edwin Zusrony, Dewi Widyaningsih

DOI: https://doi.org/10.31004/abdidas.v2i4.369

mengamati sebuah kerja kelompok yang dikerjakan outside class (Fatria, 2017). Pemateri pertama menyampaikan tentang pentingnya dapat menggunakan aplikasi Google Drive agar memudahkan guru dan wali murid dalam mendukung pembelajaran online atau daring. Pertama kali yang harus dilakukan sebelum bisa memanfaatkan fasilitas pada aplikasi Google Drive maka harus memiliki akun Gmail, di mana akun email dari Google ini akan menjadi pintu utama dalam memanfaatkan berbagai fasilitas media sosial seperti YouTube, Google Drive, Google Meet, Google Classrom, Google Form, dan lainlain. Pembuatan Google Drive dipaparkan oleh pemateri pertama dengan menggunakan media PowerPoint (PPT) serta dipraktikkan secara langsung dengan pembuatan akun Gmail untuk sekolah TK Tarbiyatul Banin 58 yang nantinya juga bisa digunakan sebagai sarana pembelajaran yang efektif, efisien serta terjangkau bagi para murid.

Materi selanjutnya adalah materi tentang pembuatan media pembelajaran berbasis multimedia, di mana pemateri pertama mengenalkan aplikasi YouTube Channel sebagai alternatif dalam mendukung Belajar dari Rumah (BDR) yang ditetapkan pemerintah sebagai sarana pencegahan Covid-19. YouTube adalah suatu software sebagai alat bantu (tools), manipulasi serta menyampaikan sebuah informasi (Baihaqi, Mufarroha, \& Imani, 2020). Sedangkan YouTube Channel merupakan aplikasi media sosial yang tidak berbayar alias gratis sehingga sangatlah cocok digunakan oleh sekolah dalam menyampaikan pemaparan materi pembelajaran sesuai kurikulum yang berlaku. Pembelajaran sekolah wajib didesain dengan mengikuti perkembangan zaman. Banyak sekali murid yang merasa jenuh atau bosan karena penyampaian materi pembelajaran biasanya berupa ceramah (Agustina, Astuti, Sumarni, \& Bhakti, 2019). Dengan adanya aplikasi YouTube Channel bisa dimanfaatkan oleh sekolah khususnya TK Tarbiyatul Banin 58 Kota Salatiga untuk menghadirkan pembelajaran multimedia yang interaktif dan menarik murid untuk semakin rajin dalam belajar. Pemateri kedua langsung memaparkan pembuatan YouTube Channel TK Tarbiyatul Banin 58 sambil mempraktikkan secara langsung dengan pembuatan akun YouTube Channel sekolah.

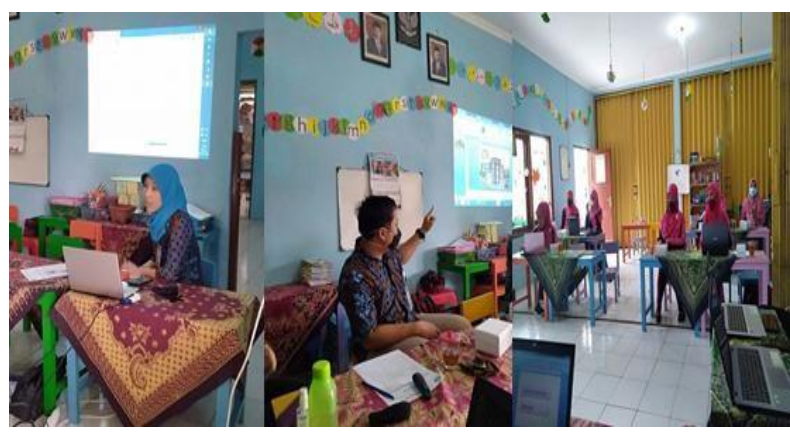

Gambar 3. Pemberian Materi Kepada Para Peserta

Semua materi pelatihan yang telah dipaparkan oleh para pemateri diberikan kepada semua peserta agar lebih bisa memahami secara mendalam serta memudahkan tim dosen Universitas STEKOM dalam melakukan pendampingan. Tahapan penyuluhan dan pelatihan ABDIMAS di TK Tarbiyatul Banin 58 diakhiri dengan sesi foto bersama antara peserta dengan tim pengabdian kepada masyarakat. 


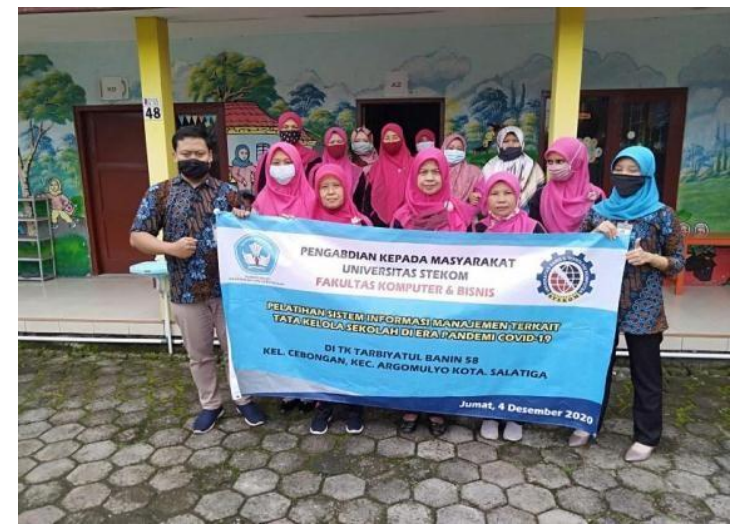

Gambar 4. Sesi Foto Bersama Setelah Akhir

ABDIMAS

Para guru di TK Tarbiyatul Banin yang diajarkan serta diliatih tentang pemanfaatan media pembelajaran berbasis multimedia hampir sebagian berpendidikan sarjana dengan usia mayoritas di atas 40 tahun serta memiliki tingkat pemahaman yang masih rendah terkait penggunaan media sosial sebagai sarana pembelajaran interaktif. Hal ini dapat dilihat dari kepemilikan akun media sosial seperti YouTube Channel yang belum memilikinya. Beberapa pertanyaan pada pretest yang telah diberikan kepada peserta, terkait:

1. Apakah memiliki akun Google Drive?,

2. Apakah memiliki akun YouTube Channel?, dan

3. Apakah bisa menggunakan kedua akun tersebut?

Hasil dari pretest ini dijadikan parameter oleh tim ABDIMAS dari Universitas STEKOM yang dapat digambarkan sebagai berikut :
HASIL PRE-TEST

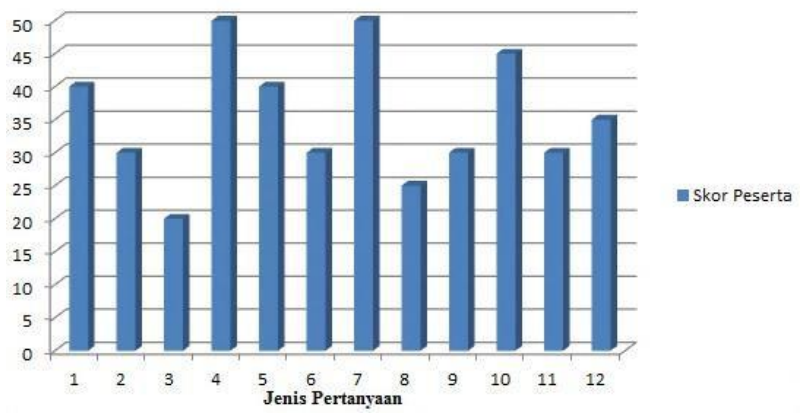

Gambar 5. Hasil Pretest Sebelum Kegiatan

Pengabdian

\section{Pendampingan Kegiatan Setelah Pelatihan}

Berdasarkan hasil wawancara dengan pertanyaan singkat sebelum kegiatan ABDIMAS dilaksanakan dengan beberapa guru TK Tarbiyatul Banin 58, masih terkendalanya sarana dan prasarana dalam mendukung pembelajaran multimedia di TK swasta dan ditambah masih kurangnya literasi digital para pengajar. Padahal sebuah teknologi dalam pembelajaran memiliki tujuan agar dapat memicu serta memacu proses belajar (Nugraha \& Sudiyono, 2018). Tim dari Universitas STEKOM akan selalu melakukan pendampingan secara lebih intensif agar tercapai tujuan dari pengabdian kepada masyarakat.

Pendampingan dilakukan oleh tim dosendari Program Studi Bisnis Universitas STEKOM dengan selalu berkomunikasi secara intensif baik dengan kepala sekolah maupun para guru di TK Tarbiyatul Banin 58 serta memantau perkembangannya melalui komunikasi virtual. Dari hasil pendampingan dapat diimplementasikan pembuatan akun email sekolah Gmail (tbanin58@gmail.com) dan Akun YouTube Channel sekolah dengan nama "TK BANIN 58". 
Hasil pendampingan oleh tim dosen dari Universitas STEKOM diperlihatkan pada gambar berikut ini :

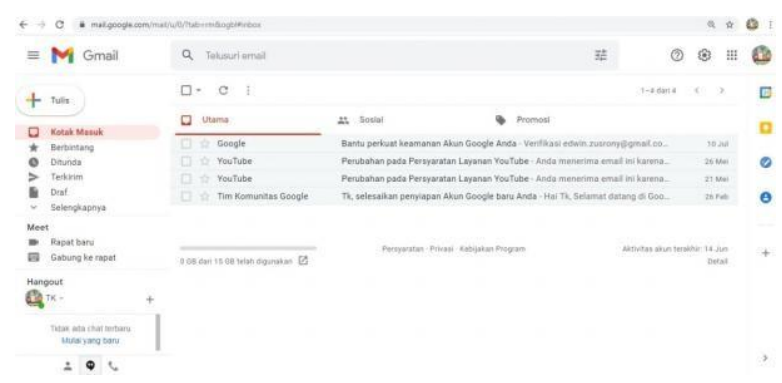

Gambar 6. Akun Gmail TK Tarbiyatul Banin 58

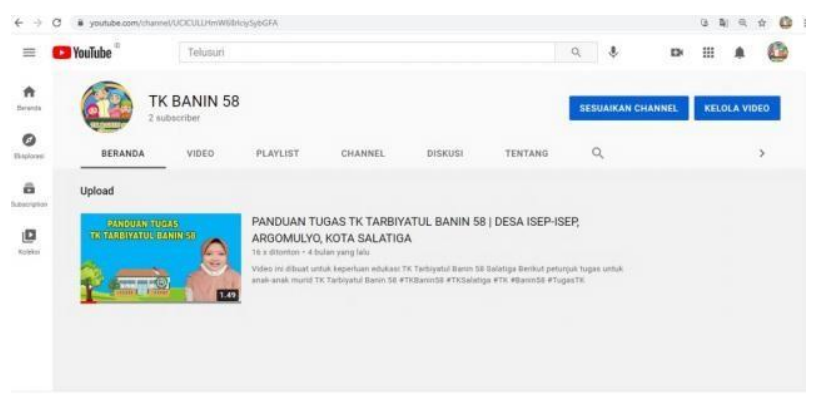

Gambar 7. YouTube TK Tarbiyatul Banin 58

Berikut perbandingan hasil pretest dengan hasil post-test terdapat pada gambar 8 di bawah ini

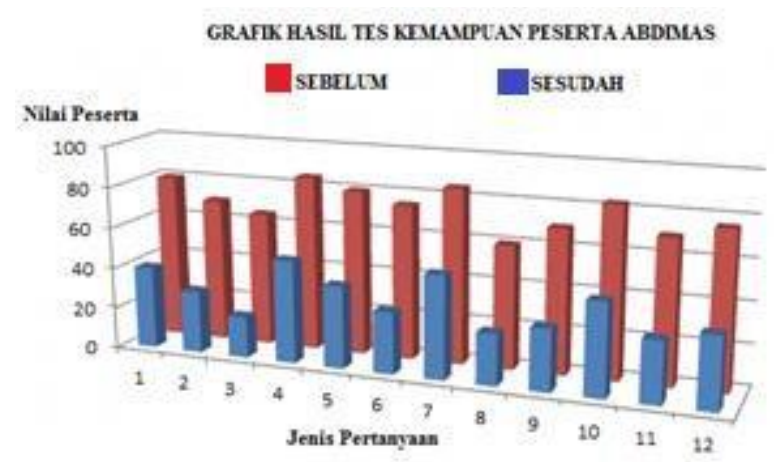

Gambar 8.Perbandingan Hasil

Pretest dan Post-test

Berdasarkan hasil post-test pada peserta setelah dilakukan pelatihan dan pendampingan dari tim dosen Universitas STEKOM terdapat kenaikkan. Berdasarkan grafik pada gambar 8 terlihat rata-rata kenaikan kemampuan peserta pengabdian kepada masyarakat sekitar 75\% ditambah dengan pendampingan yang intensif.

\section{SIMPULAN}

Puji syukur kehadirat Allah SWT, di mana seluruh kegiatan kegiatan pengabdian kepada masyarakat di TK Tarbiyatul Banin 58 berjalan secara lancar serta sudah mencapai sasaran dan tujuan serta berdampak secara positif untuk meningkatkan kemampuan para guru dalam adaptasi teknologi pembelajaran berbasis multimedia.

Pendampingan setelah kegiatan pengabdian kepada masyarakat dapat meningkatkan kemampuan para guru-guru TK Tarbiyatul Banin 58, di mana mayoritas merasa lebih memahami pemanfaatan media sosial sebagai media pembelajaran berbasis multimedia yang dibuktikan sekolah sudah memiliki akun Google Drive serta YouTube Channel.

\section{UCAPAN TERIMA KASIH}

Ucapan terima kasih penulis sampaikan kepada berbagai pihak, di antaranya Rektor, Dekan Fakultas Komputer dan Bisnis serta Ketua LPPM Universitas STEKOM yang telah membantu dan mendukung kegiatan pengabdian kepada masyarakat bisa terlaksana dengan baik. Kepala sekolah dan para guru dari TK Tarbiyatul Banin 58 di Kota Salatiga yang telah memberikan kesempatan dan memfasilitasi pada para dosen 
Universitas STEKOM untuk dapat memberikan pelatihan dan pendampingan dalam pemanfaatan media pembelajaran berbasis multimedia.

\section{DAFTAR PUSTAKA}

Agustina, I., Astuti, D., Sumarni, R. A., \& Bhakti,

Y. B. (2019). Pengembangan Multimedia Interaktif Berbasis. Abdimas Dewantara, 2(2), 107-114.

Baihaqi, A., Mufarroha, A., \& Imani, A. I. T. (2020). EDUSIANA : Jurnal Manajemen dan Pendidikan Islam YOUTUBE SEBAGAI MEDIA PEMBELAJARAN PENDIDIKAN.

Jurnal Manajemen Dan Pendidikan Islam, 7(1), 74-88.

Busa, Y. (2020). Bimbingan Teknis Pembuatan Media Pembelajaran Digital secara daring oleh civitas akademika ditengah pandemi Covid-19. CARADDE: Jurnal Pengabdian Kepada Masyarakat, 3(1), 158-165.

Fatria, F. (2017). Penerapan Media Pembelajaran Google Drive dalam Pembelajaran Bahasa Indonesia. Jurnal Penelitian Pendidikan Bahasa Dan Sastra, 2(1), 138-144.

Hamidah, H., \& Marsiah, M. (2020). Pembelajaran Maharah Al-Istima' dengan Memanfaatkan Media Youtube: Problematika dan Solusi. AlTa'rib: Jurnal Ilmiah Program Studi Pendidikan Bahasa Arab IAIN Palangka Raya, 8(2), 147-160.

https://doi.org/10.23971/altarib.v8i2.2282 Ismail, I., Gunaisah, E., Ulat, M. A., Muhfizar, M.,

Poltak, H., Teknik, S., ... Perikanan, T. B. (2021). Pelatihan Teknologi Sistem Informasi bagi Nelayan pada Masa Covid-19 di Era Digital. DINAMISIA: Jurnal Pengabdian Kepada Masyarakat, 5(3), 566-574.

Nugraha, D. A., \& Sudiyono, S. (2018). Pelatihan Dan Pendampingan Pembuatan Media Pembelajaran Interaktif Menggunakan Autoplay Media Studio Bagi Guru-Guru Sdn Merjosari 1. Jurnal Terapan Abdimas, 3(2), 182. https://doi.org/10.25273/jta.v3i2.2811 Retnoningsih, E., Retnoningsih, E., Solikin, S.,
Muis, I., \& Widiawati, K. (2021). Pelatihan Pembelajaran Jarak Jauh Dengan Google Drive Dan Google Form Untuk Guru. Journal Of Computer Science Contributions (JUCOSCO), 1(1),17-27.

https://doi.org/10.31599/jucosco.v1i1.441 Sibero, A. F. K., \& Manurung, I. H. G. (2020).

Pelatihan Penggunaan Google ClassroomSebagai Media Pembelajaran Dan EvaluasiGuru Di Smk Negeri 11 Medan. JurnalAbdimas Mutiara, 1(September), 107-114.Retrieved from http://e-journal.sari-

mutiara.ac.id/index.php/JAM/article/view/13 19

Wardani, A., \& Ayriza, Y. (2021). Analisis Kendala Orang Tua dalam Mendampingi Anak Belajar di Rumah Pada Masa Pandemi Covid-19. Jurnal Obsesi : Jurnal Pendidikan Anak Usia Dini, 5(1), 772-782. https://doi.org/10.31004/obsesi.v5i1.705 